\title{
Pengaruh Model Pembelajaran CIRC dengan Strategi MURDER Terhadap Kemampuan Koneksi Matematis Peserta Didik di SMA Negeri 1 Sungkai Utara
}

\author{
Titiana Nurjani Nasution ${ }^{1}$, Netriwati ${ }^{2}$, Novian Riskiana Dewi ${ }^{3}$ \\ 1, 2,3 Program Studi Pendidikan Matematika, Fakultas Tarbiyah dan Keguruan, Universitas Islam Negeri Raden Intan Lampung, \\ J1. Letnan Kolonel H. Endro Suratmi, Sukarame, Kota Bandar Lampung, Lampung, Indonesia \\ titiananasution2@gmail.com
}

\begin{abstract}
This study aims to determine the difference in mathematical connection abilities between students who use the CIRC learning model and the MURDER strategy and students who use conventional learning models. This type of research is quantitative, using a quasi-experimental design research method, and the design used is a post-test only control group design. The sampling technique used is cluster random sampling. The samples of this study were students of class X MIA 2 as the experimental class and students of class X MIA 3 as the control class. Sig obtained by using SPSS 23.0 for windows based on $\mathrm{t}$ test. (2-tailed) $=0.37<=0.05$, which means that there is a significant difference in mathematical connection ability between students who receive the MURDER strategy CIRC learning model and students who receive conventional learning. Based on the calculation of the effect size, the effect size value is 0.51 which indicates that the CIRC learning model with the MURDER strategy has a moderate contribution to the ability of students' mathematical connections to Indonesia.
\end{abstract}

Keywords: mathematical connection ability, CIRC, MURDER.

\begin{abstract}
Abstrak
Penelitian ini bertujuan untuk mengetahui perbedaan kemampuan koneksi matematis antara peserta didik yang menggunakan model pembelajaran CIRC dan strategi MURDER dengan siswa yang menggunakan model pembelajaran konvensional. Jenis penelitian ini adalah kuantitatif, menggunakan metode penelitian quasy experimental design, dan desain yang digunakan adalah post-test only control group design. Teknik pengambilan sampel yang digunakan adalah cluster random sampling. Sampel penelitian ini adalah siswa kelas X MIA 2 sebagai kelas eksperimen dan siswa kelas X MIA 3 sebagai kelas kontrol. Signifikansi diperoleh dengan menggunakan SPSS 23.0 for windows berdasarkan uji $\mathrm{t}(2$-tailed $)=0,37<\alpha=0,05$ yang berarti terdapat perbedaan yang signifikan kemampuan koneksi matematis antara peserta didik yang menerima model pembelajaran CIRC strategi MURDER dan peserta didik yang menerima pembelajaran konvensional. Berdasarkan perhitungan Effect Size diperoleh nilai Effect size sebesar 0,51 yang menunjukkan bahwa model pembelajaran CIRC dengan strategi MURDER memiliki kontribusi yang sedang terhadap kemampuan koneksi matematis peserta didik.
\end{abstract}

Kata kunci: kemampuan koneksi matematis, CIRC, MURDER

Copyright (c) 2021 Titiana Nurjani Nasution, Netriwati, Novian Riskiana Dewi

$\triangle$ Corresponding author: Titiana Nurjani Nasution

Email Address: titiananasution2@ gmail.com (Jl. Letnan Kolonel H. Endro Suratmi, Kota Bandar Lampung, Lampung)

Received 09 June 2021, Accepted 05 July 2021, Published 15 July 2021

\section{PENDAHULUAN}

Matematika merupakan salah satu cabang ilmu pengetahuan dan memegang peranan penting dalam perkembangan teknologi dan ilmu pengetahuan, sehingga dapat digunakan sebagai alat aplikasi untuk mata pelajaran lain dan pengembangan matematika itu sendiri(Siagian, 2016). Mata pelajaran matematika adalah salah satu mata pelajaran yang memiliki manfaat besar dalam kehidupan. Matematika memberi peserta didik kesempatan untuk melatih pikiran mereka dan dapat mempengaruhi pengembangan intelektual mereka. Melalui mata pelajaran matematika peserta didik dapat pelajaran untuk memperoleh suatu ilmu sistematis (Syafitri, et al. 2018). 
Salah satu kemampuan dasar yang seharusnya dimiliki oleh peserta didik adalah kemampuan koneksi matematis. Menurut NCTM (National Council of Teacher of Mathematics) koneksi matematis adalah hubungan antara topik matematika, hubungan antara matematika dengan mata pelajaran lain, dan hubungan antara matematika dengan dunia nyata atau kehidupan sehari-hari (Romli, 2017). Pengertian lain dari koneksi matematis yaitu keterampilan berpikir tinggi yang menghubungkan berbagai konsep dalam matematika (termasuk hubungan internal dan eksternal yang berkaitan dengan ilmu matematika, hubungan dengan bidang matematika lainnya dalam kehidupan sehari-hari) (Ni’mah, Setiawani, and Oktavianingtyas, 2017). Menurut Sumarmo dalam (Lubis, 2019) indikator koneksi matematis sebagi berikut: 1) menemukan hubungan antar konsep, prosedur, dan topik pelajaran matematika; 2) mencari hubungan antara topik pelajaran matematika dengan topik pelajaran bidang studi lain ;3) menentukan representasi ekuivalen suatu konsep matematika.

Disimpulkan bahwa kemampuan koneksi yaitu kemampuan untuk menjalin hubungan antara konsep matematika dan antara konsep, matematika di bidang lain dan kehidupan sehari-hari (Nurafni and Pujiastuti, 2019). Dan indikator indikator koneksi matematis yang terbagi tiga, yaitu: 1) koneksi antar topik dalam matematika; 2) koneksi matematika dengan bidang studi lain; dan 3) koneksi matematika dengan kehidupan sehari-hari (Jahring, 2020). Matematika adalah ilmu yang tidak dapat dipisahkan dalam permasalahan di kehidupan sehari-hari. Kemampuan koneksi matematis dibutuhkan karena pelajaran matematika adalah bagian yang terdiri dari beberapa topik yang tidak dapat dibagi.

Rendahnya koneksi matematis peserta didik sangat berpengaruh dalam pembelajaran, seperti yang dijumpai dilapangan menunjukkan bahwa kemampuan koneksi matematis peserta didik masih jauh dari harapan. Hal ini berdasarkan wawancara yang dilakukan oleh peneliti dengan salah satu pendidik mata pelajaran matematika di SMA Negeri 1 Sungkai Utara. Peneliti memperoleh informasi bahwa koneksi matematis peserta didik yang masih rendah dapat diketahui bahwa peserta didik belum mampu menyerap indikatorindikator koneksi matematis. Hasil tes yang dilakukan pendidik sebagai evaluasi pembelajaran membuktikan bahwa dengan nilai KKM (Kriteria Ketuntasan Minimum) sebesar 72 untuk matapelajaran matematika masih banyak peserta didik yang belum tuntas. Hal ini karena peserta didik tidak berpartisipasi secara aktif dalam kegiatan pembelajaran. Menurut (Afifah, 2017) dalam penelitiannya mengatakan terdapat faktor-faktor yang mempengaruhi tinggi rendahnya kemampuan koneksi matematis. Sehingga perlu sebuah penelitian lanjutan yang menerapkan model pembelajaran lain yang mampu dapat meningkatan kemampuan koneksi matematis.

Permasalahan diatas membuktikan jika koneksi matematis peserta didik saat ini masih rendah maka perlu diperhatikan. Masalah ini tidak hanya datang dari peserta didik, tetapi juga dipengaruhi oleh model pembelajaran yang digunakan pendidik. Turmudi dalam (Rahma Johar, dan Said Munzir, 2016) menyakini bahwa proses dalam pembelajaran matematika saat ini dikomunikasikan fokus terhadap peserta didik secara informatif, peserta didik hanya mendapatkan informasi dan tidak dilibatkan dalam menemukan konsep-konsep materi yang seharusnya dikuasai. Oleh karena itu, peserta didik perlu terbiasa berdebat 
untuk setiap materi pelajaran dan menanggapi tanggapan peserta didik lain. Hal ini dapat memjadikan peserta didik lebih merasakan makna pelajaran yang telah dipelajarinya.

Alternatif penerapan model pembelajaran kooperatif tipe CIRC dalam pembelajaran matematika di ruang kelas dapat menjadikan peserta didik tidak merasakan bosan dengan pembelajaran yang biasa dilakukan (Margono, 2013). Cooperative learning berasal dari kata cooperative yang mempunyai arti membantu satu sama lain dalam kelompok atau tim untuk melakukan sesuatu bersama (Anwar, 2017). Salah satu tipe dari cooperative learning adalah model pembelajaran CIRC (Cooperative Integrated Reading and Composition) yang dikembangkan oleh Stevans, Madden, Slavin, dan Farnish. Terjemahan dari CIRC (Cooperative Integrated Reading And Composition) adalah komposisi terpadu membaca dan menulis secara kooperatif/kelompok (Shoimin, 2014). Dengan model pembelajaran CIRC (Cooperative Integrated Reading and Composition) proses pembelajaran akan menjadi hidup karena peserta didik akan terlibat untuk lebih membaca dan memahami secara menyeluruh materi, kemudian peserta didik meringkas materi menjadi bagian-bagian penting seperti pengertiannya, rumus, hingga penyelesaian soal yang akan menjadikan peserta didik lebih aktif.

Dalam penelitian (Margianto, 2017) mengatakan bahwa terdapat peningkatan hasil belajar pada peserta didik dengan penerapan model pembelajaran cooperative learning tipe CIRC, dapat dilihat dari antusias belajar peserta didik meningkat, keberanian peserta didik menanyakan materi yang belum paham semakin banyak, peserta didik yang menanggapi pendapat peserta didik lain semakin meningkat, dan meningkatkan antusias peserta didik dalam mengerjakan soal latihan.

Model pembelajaran CIRC (Cooperative Integrated Reading and Composition) akan dibantu dengan strategi MURDER. Karena pembelajaran menggunakan strategi ini bertujuan agar peserta didik mampu untuk lebih mandiri dan memonitor cara pembelajaran peserta didik sendiri sehingga mampu memahami pelajaran (Jafar, 2019). Strategi MURDER merupakan salah satu strategi pembelajaran, MURDER memiliki arti yaitu pembelajaran kognitif yang melatih kemampuan peserta didik dalam membangun ulang informasi dan ide yang diterima serta memahaminya kemudian mengkomunikasikan secara lisan dan tulisan (Mayangsari and Wahono, 2015).

Enam kata pembentuk MURDER yaitu Mood, Understand, Recall, Digest, Expand, dan Review.Pada tahun 1979, pertama kali Dansereau memunculkan pembelajaran MURDER sebagai salah satu bentuk pembelajaran kooperatif. Membentuk sikap dan mood belajar yang positif untuk belajar merupakan arti dari Mood, memahami apa yang sedang dipelajari merupakan arti dari Understand, memanggil kembali pengetahuan yang telah diingat merupakan arti dari Recall, memeriksa kembali kebenaran dan menemukan kesalahannya merupakan arti dari Digest, mengembangkan pengetahuan merupakan arti dari Expand, dan yang terakhir meninjau apa yang telah dikerjakan merupakan arti dari Review (Sumartini, 2017).

Menurut penelitian (Jafar, 2019), dimana hasil dari penelitian ini mengatakan bahwa strategi MURDER menyebabkan peserta didik dalam proses pembelajaran lebih aktif dan bertukar pendapat dalam diskusi untuk menambah wawasan. Dengan bantuan strategi MURDER diharapkan model pembelajaran CIRC (Cooperative Integrated Reading and Composition) menjadi dapat berpengaruh terhadap kemampuan 
koneksi matematis peserta didik. Model pembelajaran CIRC (Cooperative Integrated Reading And Composition) diharapkan dapat mengubah pemikiran peserta didik terhadap matematika yang semula menganggap sebagai mata pelajaran yang membosankan dan menakutkan menjadi lebih mengasyikkan. Dengan itu diharapkan peserta didik dapat memahami koneksi matematis yang baik.

Berdasakan permasalah tersebut, penulis merasa tertarik untuk melakukan suatu penelitian dengan menerapkan model pembelajran CIRC dengan strategi MURDER dengan melibatkan peserta didik aktif dengan indikator kemampuan koneksi matematis 1) koneksi antar topik dalam matematika; 2) koneksi matematika dengan bidang studi lain; dan 3) koneksi matematika dengan kehidupan sehari-hari. Sehinggan penulis akan melakukan penelitian dengan judul "Pengaruh Model Pembelajaran CIRC dengan Strategi MURDER Terhadap Kemampuan Koneksi Matematis Peserta Didik di SMA Negeri 1 Sungkai Utara.”

\section{METODE}

Pada Penelitian ini digunakannya pendekatan kuantitatif yang merupakan salah satu cara untuk pencarian ilmiah. Peneliti akan menggunakan jenis penelitian yaitu Quasy Eksperimental Design atau bisa disebut dengan ekperimen semu yang memiliki kelompok kontrol namun tidak digunakan untuk mengontrol variabel dari luar yang berpengaruh dengan terlaksananya eksperimen (Sugiono, 2016). Rancangan penelitian yaitu berbentuk Posttest Only Control Group Design. Ranvangan penelitian dapat digambarkan sebagai berikut:

Tabel 1. Desain penelitian

\begin{tabular}{|c|c|c|}
\hline Group & Perlakuan & Posstest \\
\hline Eksperimen & $\mathrm{X}$ & $\mathrm{O}_{1}$ \\
\hline Kontrol & - & $\mathrm{O}_{1}$ \\
\hline
\end{tabular}

Sumber: (Sugiono, 2015)

Pada metode ini digunakan dua kelas yaitu kelas eksperimen dan kelas kontrol. Populasi pada penelitian ini adalah seluruh peserta didik kelas X SMA Ngeri 1 Sungkai Utara. Sampel dalam penelitian ini adalah kelas X MIA 2 berjumlah 36 peserta didik dan kelas X MIA 3 berjumlah 36 peserta didik yang dipilih secara random sampling. Sampel ini berguna untuk menentukan satu kelas eksperimen dan satu kelas kontrol. Di kelas eksperimen akan menerima pembelajaran dengan menerapkan model pembelajaran CIRC dengan strategi MURDER, dan kelas kontrol akan menerapkan pembelajaran dengan model konvensional. Dalam penelitian ini kelas X MIA 2 sebagai kelas eksperimen dan kelas X MIA 3 sebagai kelas kontrol.

Variabel bebas dalam penelitian ini adalah model pembelajaran CIRC dengan strategi MURDER, sedangkan variabel terikat adalah kemampuan koneksi matematis peserta didik. Instrumen penelitian ini adalah test dimana test ini untuk mengetahui ada tidaknya perbedaan pengaruh model pembelajaran CIRC dengan strategi MURDER dan pembelajaran metode pembelajaran langsungterhadap kemampuan koneksi matematis peserta didik pada materi pelajaran trigonometri.

Pada instrumen penelitian dilakukan uji validitas dan uji reliabilitas berbantuan SPSS 23.0 for windows setelah itu dilanjutkan dengan uji tingkat kesukaran dan uji daya beda. Dari keempat uji tersebut 
didapatkan hasil yaitu valid serta reliabel sehingga instrumen penelitian layak digunakan dalam penelitian. Terdapat teknik analisis data yang terdiri dari uji prasyarat dan uji hipotesis. Pada uji prasyarat ada uji normalitas yang menggunakan Kolmogorov Smirnov pada SPSS 23.0 for windows dan adapun uji homogenitas yang menggunakan uji homogeneity of variance pada SPSS 23.0 for windows. Pada uji hipotesis akan menggunakan uji t. Uji t dibantu dengan menggunakan program aplikasi SPSS 23.0 for windows. Penelitian ini dilakukan di SMA Negeri 1 Sungkai Utara. Penelitian ini dilakukan pada bulan Maret sampai April 2021.

\section{HASIL DAN DISKUSI}

Pada penelitian ini melibatkan peserta didik dari dua kelas di SMA Negeri 1 Sungkai Utara, yaitu kelas X MIA 2 yang berjumlah 36 peserta didik dan kelas X MIA 3 yang berjumlah 36 peserta didik. Kelas X MIA 2 sebagai kelas eksperimen mendapatkan perlakuan pengajaran menggunakan model pembelajaran CIRC dengan strategi MURDER dan Kelas X MIA 3 sebagai kelas kontrol mendapatkan perlakuan pengajaran menggunakan model pembelajaran langsung. Kemudia siswa diberikan posttest berupa soal essay sebanyak 4 soal untuk mengetahui kemampuan koneksi matematis peserta didik setelah masing-masing kelas diberikan perlakuan. Perolehan hasil data posttest yang disajika dengan menggunakan Mscrosoft Excel sebagai berikut.

Tabel 2 Deskriptif frekuensi kemampuan koneksi matematis

\begin{tabular}{|l|l|r|r|l|r|r|r|l|}
\hline Kelompok & N & Maks & Min & Mean & Median & Modus & Range & Sdt. Deviasi \\
\hline Eksperimen & 36 & 100 & 46 & 74,25 & 70 & 75 & 54 & 10,81 \\
\hline Kontrol & 36 & 90 & 42 & 67,5 & 65 & 65 & 48 & 13,07 \\
\hline
\end{tabular}

Dari data hasil posttest yang telah diberikan kepada masing-masing kelas pada Tabel 2 dapat disimpulkan bahwa hasil dari kelas eksperimen yang mendapatkan perlakuan pengajaran menggunakan model pembelajaran CIRC dengan strategi MURDER lebih baik dibandingkan kelas kontrol yang mendapatkan perlakuan pengajaran menggunakan model pembelajaran langsung.

Berdasarkan hasil posttest yang telah dilakukan, data diuji apakah data tersebut berdistribusi normal atau tidak, untuk itu dilakukan analisis dari perhitungan hasil tes dengan bantuan SPSS 23.0 for windows. Uji yang digunakan adalah uji kolmogrov-smirnov yang diperoleh hasil uji yang telah dirangkum seperti berikut ini.

Tabel 3. Uji Normalitas Nilai Posstest Kelas Eksperimen dan Kontrol

\begin{tabular}{|l|l|r|r|r|r|r|r|}
\hline \multicolumn{10}{|c|}{ Tests of Normality } \\
\hline \multirow{2}{*}{ Kelas } & \multicolumn{3}{|c|}{ Kolmogorov-Smirnov $^{\text {a }}$} & \multicolumn{3}{c|}{ Shapiro-Wilk } \\
\cline { 3 - 9 } & Statistic & \multicolumn{1}{|c|}{ df } & \multicolumn{1}{c|}{ Sig. } & \multicolumn{1}{c|}{ Statistic } & \multicolumn{1}{c|}{ df } & \multicolumn{1}{c|}{ Sig. } \\
\hline \multirow{2}{*}{ Nilai } & Eksperimen & .095 & 36 & $.200^{*}$ & .979 & 36 & .717 \\
\cline { 2 - 9 } & Kontrol & .106 & 36 & $.200^{*}$ & .967 & 36 & .347 \\
\hline
\end{tabular}


Hasil perhitungan uji normalitas koneksi matematis dilihat dari KolmogrovSmirnov dengan melihat nilai Sig pada kelas eksperimen yang diberikan model pembeljaran CIRC dengan strategi MURDER yaitu 0,200 lebih besar dari nilai $\alpha=0,05$ maka $\mathrm{H}_{0}$ diterima. Dengan demikian menunjukkan bahwa kelas eksperimen pada matematis dan koneksi matematis pada penelitian ini berasal dari populasi yang berdistribusi normal. Begitu juga dengan nilai Sig pada kelas kontrol yang diberikan model pembelajaran pembelajaran langsungyaitu 0,200 lebih besar dari nilai $\alpha=0,05$ maka $\mathrm{H}_{0}$ diterima. Sehingga menunjukkan bahwa kelas kontrol pada matematis dan koneksi matematis pada penelitian ini berasal dari populasi yang berdistribusi normal.

Pengujian homogentias ini bertujuan untuk memastikan bahwa varians data dari kedua kelas tersebut bersifat homogeny, sehingga meminimalisir factor yang memperngaruhi hasil penelitian yang akan dilakukan. Adapun output uji homogentias yang dilakukan dengan analisis test of homogeneity of varians melalui bantuan SPSS 23.0 sebagai berikut.

Tabel 4. Hasil Uji Homogenitas

\begin{tabular}{|c|c|c|c|c|}
\hline \multicolumn{5}{|c|}{ Levene's Test of Equality of Error Variances $^{\boldsymbol{a}}$} \\
\hline & F & df1 & df2 & Sig. \\
\hline Koneksi Matematis & 2.41 & 1 & 70 & 0.125 \\
\hline
\end{tabular}

Didapatkan dari hasil tes diatas pada kelas eksperimen dan kontrol yaitu 0,125 dengan nilai $\alpha=0,05$ atau $5 \%$ maka Sig $>\alpha$, maka H0 diterima. Dapat disimpulkan bahwa variansi pada setiap kelompok sama atau homogen baik pada kemampuan koneksi matematis. Sehingga kedua kelas termasuk data yang homogen. Karena varians kedua kelas bersifat homogeny maka penelitian dapat dilanjutkan ketahap berikutnya.

Setelah uji prasyarat telah dilakukan kemudia dilakukan uji hipotesis. Pengujian hipotesis dilakukan menggunakan uji t. Tujuan pengujian ini untuk melihat ada atau tidaknya pengaruh model pembelajaran CIRC dengan strategi MURDER terhadap koneksi matematis peserta didik. Hasil uji t yang telah dilakukan di kelas eksprimen dan kontrol sebagai berikut:

Tabel 4. Hasil Uji-t Posttest Kelas Eksperimen dan Kontrol

\begin{tabular}{|c|c|c|c|}
\hline \multicolumn{4}{|c|}{ Independent Samples Test } \\
\hline & & $\begin{array}{l}\text { Equal } \\
\text { variances } \\
\text { assumed }\end{array}$ & $\begin{array}{l}\text { Equal } \\
\text { variances } \\
\text { not } \\
\text { assumed }\end{array}$ \\
\hline \multirow{2}{*}{ Levene's Test for Equality of Variances } & $\mathrm{F}$ & 3.819 & \\
\hline & Sig. & 0.055 & \\
\hline \multirow{4}{*}{ Equal variances not assumed } & $\mathrm{T}$ & 2.123 & 2.123 \\
\hline & Df & 70 & 66.021 \\
\hline & Sig. (2-tailed) & 0.037 & 0.038 \\
\hline & Mean Difference & 5.86111 & 5.86111 \\
\hline
\end{tabular}




\begin{tabular}{|ll|r|r|} 
& Std. Error Difference & 2.76131 & 2.76131 \\
\hline \multirow{2}{*}{ 95\% Confidence Interval of the Difference } & Lower & 0.35385 & 0.34801 \\
\cline { 2 - 4 } & Upper & 11.36837 & 11.37422 \\
\hline
\end{tabular}

Berdasarkan Tabel 4 nilai Sig. (2-tailed) $=0.037$, karena $0.037<\alpha=0.05$, sehingga $\mathrm{H}_{0}$ ditolak dan $\mathrm{H}_{\mathrm{a}}$ diterima, yang artinya terdapat pengaruh model pembelajaran CIRC dengan strategi MURDER terhadap kemampuan koneksi matematis peserta didik di SMA Negeri 1 Sungkai Utara.

Untuk mengetahui seberapa besar kontribusi (effect Size) pembelajarn yang menggunakan model CIRC dengan strategi MURDER terhadap kemampuan koneksi matematis peserta didik, menggunakan perhitungan sebagai berikut:

$$
E S=\frac{\overline{X_{e}}-\overline{X_{c}}}{s d_{c}}=\frac{74,25-67,5}{13,07}=0,51
$$

Berdasarkan perhitungan tersebut maka nilai Effect Size termasuk dalam kriteria, 0,2 $>$ Es $\leq 0,8$, yang artinya nilai Effect Size tergolong sedang. Sehingga dapat disimpulkan bahwa pembelajaran yang menggunakan model pembelajarn CIRC dengan strategi MURDER terhadap kemampuan koneksi matematis peserta didik di SMA Negeri 1 Sungkai Utara memberikan kontribusi (Effect Size) yang tergolong sedang yaitu sebesar 0,51 .

Berdasarkan perhitungan Effect Size dapat diketahui bahwa pembelajaran dengan menggunakan model pembelajaran CIRC dengan strategi MURDER memberikan kontribusi sedang, yaitu dengan nilai Effect Size sebesar 0,51. Meskipun demikian, nilai posttest masih dirasa kurang memuaskan. Hal ini terlihat bahwa 53\% peserta didik memperoleh nilai dibawah Kreteria Ketuntasan Minimum (KKM) yang digunakan di SMA Negeri 1 Sungkai Utara yaitu 72. Tidak maksimalnya hasil belajar peserta didik dikarenakan keterbatasan peneliti. Ketika pembelajaran berlangsung ada beberapa peserta didik yang tidak setuju dengan anggota kelompoknya sehingga peserta didik terlihat kurang aktif dalam pembelajara dengan kata lain peserta didik tersebut tidak mengikuti pembelajaran dengan baik. Selain itu, ada kelompok yang memerlukan bantuan peneliti hampir disetiap permasalahan yang diberikan sehingga dapat mengurangi kebermaknaan pembelajaran.

\section{KESIMPULAN}

Berdasarkan pengujian hipotesis menggunakan program SPSS 23.0 for windows diperoleh hasil pengelolahan uji t (independent samples $T$ test) dengan nilai Sig. (2-tailed) $=0.37$, karena $0.37<\alpha=0.05$, sehingga berdasarkan criteria pengujian hipotesis dapat disimpulkan $\mathrm{H}_{0}$ ditolak dan $\mathrm{H}_{\mathrm{a}}$ diterima. Dengan kata lain terdapat perbedaan yang signifikan kemampuan koneksi matematis antara peserta didik yang diberi model pembelajaran CIRC dengan strategi MURDER dan peserta didik yang diberi model pembelajaran konvensional. Berdasarkan perhitungan Effect Size, diperoleh nilai effect size sebesar 0,51 sehingga termasuk dalam kriteria 0,2 < Es 0,8, yang artinya nilai Effect Size tergolong sedang. Sehingga dapat disimpulkan bahwa pembelajaran yang menggunakan model pembelajaran CIRC dengan strategi MURDER terhadap kemampuan koneksi matematis peserta didik pada materi trigonometri di kelas X SMA 
Negeri 1 Sungkai Utara memberikan kontribusi (Effect Size) yaitu sebesar 0,51 yang tergolong sedang. Berdasarkan hasil posttest peserta didik, diperoleh nilai yang kurang memuaskan hal ini terlihat bahwa 53\% peserta didik memperoleh nilai dibawah Kreteria Ketuntasan Minimum (KKM) yang digunakan. Namun demkian berdasarkan kesimpulan uji t (independent samples $T$ test) dan Effect Size dapat terlihat bahwa pembelajaran CIRC dengan strategi MURDER memberikan pengaruh terhadap koneksi matematis peserta didik.

Penggunaan model pembelajaran CIRC dengan strategi MURDER sangat efektif terhadap kemampuan koneksi matematis peserta didik ikut berperan lebih aktif dalam proses pembelajaran. Meskipun pada masa pandemic covid-19 ini, tetapi proses pembelajaran berjalan lancar tetapi setiap kelas diberi shift yang berbeda agar selalu menjaga jarak aman. Bagi pendidik diharapkan menggunakan model, strategi atau sumber belajar yang lebih beragram salah satu CIRC dengan strategi MURDER agar suasa belajar lebih komunikatif dan peserta didik mampu berperan aktif dalam pembelajaran. Bagi penelitian selanjutnya dapat menggunakan model pembelajaran CIRC dengan strategi MURDER sebagai solusi untuk kemampuan koneksi matematis.

\section{REFERENSI}

Afifah, R. N. (2017). Kemampuan Koneksi Matematis Pada Bangun Ruang Sisi Lengkung. Seminar Matematika Dan Pendidikan Matematika Uny, 619-624.

Anwar, C. (2017). Teori-Teori Pendidikan Klasik Hingga Kontemporer. Ircisod.

Jafar, A. F. (2019). Implementasi Strategi Belajar Kooperatif Murder Terhadap Pemahaman Konsep Fisika. Jurnal Pendidikan Fisika, 7 No. 1, 26-30.

Jahring. (2020). Kemampuan Koneksi Matematis Pada Model Pembelajaran Core Dan Nht. Aksioma: Jurnal Program Studi Pendidikan Matematika, 9(1), 182-189. Https://Doi.Org/10.24127/Ajpm.V9i1.2667

Lubis, R. (2019). Peningkatan Kemampuan Koneksi Matematis Siswa Melalui Pendekatan Open-Ended Pada Siswa Sekolah Menengah Pertama. Jurnal Gantang, 4(2), 121-132. Https://Doi.Org/10.31629/Jg.V4i2.1367

Margianto, N. (2017). Peningkatan Hasil Belajar Matematika Melalui Implementasi Metode Pembelajaran Cooperative Learning Tipe Cooperative Learning Integrated Reading And Composition (Circ) Pada Siswa Sma Negeri 1 Punggur. Jurnal Pendidikan Matematika Fkip Um Metro, 6 No. 1, 107-114.

Margono, S. (2013). Metodologi Penelitian Pendidikan. Pt. Rineka Cipta.

Mayangsari, P. W., \& Wahono, B. (2015). Pengaruh Strategi Pembelajaran Murder (Mood, Understand, Recall,Digest, Expand , Review ) Berbasis Media Interaktif Flash Terhadap Kemampuan Berpikir Kritis , Metakognisi Dan Pencapaian Hasil Belajar Siswa. Jurnal Edukasi Unej, 2, 7-11.

Ni'mah, A. F., Setiawani, S., \& Oktavianingtyas, E. (2017). Analisis Kemampuan Koneksi Matematika Siswa Kelas Ix A Mts Negeri 1 Jember Subpokok Bahasan Kubus Dan Balok. Jurnal Edukasi, 4(1), 30. Https://Doi.Org/10.19184/Jukasi.V4i1.5087 
Nurafni, A., \& Pujiastuti, H. (2019). Analisis Kemampuan Koneksi Matematis Ditinjau Dari Self Confidence Siswa: Studi Kasus Di Smkn 4 Pandeglang. Anargya: Jurnal Ilmiah Pendidikan Matematika, 2(1). Https://Doi.Org/10.24176/Anargya.V2i1.3013

Rahma Johar, Dan Said Munzir, R. F. (2016). Peningkatkan Kemampuan Pemahaman Dan Penalaran Matematis Melalui Pendekatan Kontekstual. Jurnal Didaktika Matematika, 3, 48.

Romli, M. (2017). Profil Koneksi Matematis Siswa Perempuan Sma Dengan Kemampuan Matematika Tinggi Dalam Menyelesaikan Masalah Matematika. Jipmat, 1(2), 145-157. Https://Doi.Org/10.26877/Jipmat.V1i2.1241

Shoimin, A. (2014). 68 Model Pembelajaran Inovatif Dalam Kurikulum 2013. Ar-Ruzzz Media.

Siagian, M. D. (2016). Kemampuan Koneksi Matematik Dalam Pembelajaran Matematika. Journal Of Mathematics Education And Science, 1 No. 2, 60.

Sugiono. (2015). Metode Penelitian Kuantitatif, Kualitatif, Dan $R \& D$. Alfabeta.

Sugiono. (2016). Metode Penelitian Kuantitatif, Kualitatif, Dan R\&D. Alfabeta.

Sumartini, T. S. (2017). Pembelajaran Mood, Understand, Recall, Detect, Elaborate, And Review (Murder) Berbasis Proyek Dalam Pembelajaran Matematika. Jurnal Mosharafa, 6(September), 74-80.

Syafitri, Q., Mujib, Anwar, C., Netriwati, \& Wawan. (2018). The Mathematics Learning Media Uses Geogebra On The Basic Material Of Linear Equations. Al-Jabar: Jurnal Pendidikan Matematika, 9. 